\title{
DEVELOPMENT OF A UNIVERSAL MODEL OF E-COURSE USING PETRI NETS
}

\author{
Zoltán Balogh, Martin Magdin, Milan Turčáni \\ Constantine the Philosopher University in Nitra, Slovakia \\ E-mail: zbalogh@ukf.sk,mmagdin@ukf.sk, mturcani@ukf.sk
}

\begin{abstract}
In modelling and process simulation the aim of the research is to create a designed functional control model of student communication in LMS system by a created model in Petri nets. The model reflects the student's and the pedagogue's requirements, is enough modular, not too complicated and it fulfils the basic pedagogical and psychological principles. The aim was to create a control model of student communication in LMS system which would be not only intelligible and clear but it would also eliminate some lacks from the other known models. Introduction and administration of any processes requires description of their solution, inspection, monitoring, optimization and first of all their simple formulation, whereby it is very important to express their logic. The article deals with modelling and subsequent simulation of education processes in Petri nets implemented into the environment of the learning management system (LMS). The aim of the LMS system for the teaching control is to regulate the communication according to the student's knowledge and ability and thus modify the amount and sophistication of submitted materials for the student. Using the constituted model we shall be able to create electronic courses, so these models can serve as a prototype for creating further electronic courses in the environments of the LMS.
\end{abstract}

Key words: educational process, modeling process, Petri nets, universal model, web-based education.

\section{Introduction}

In the last decade, there have been changes not only in the educational system in Slovakia, but mostly in the way how the academic knowledge has been given to students to develop their psychomotor skills and competence in a large extent. Generally, we can note that the educational process is very complicated and demanding because the teacher and the pupil are entering into multilaterally relations.

Since the moment in which the teaching machines, later computers and computer networks entered the human learning the new question emerged: how to control the human learning, whatever to take into account, in order the learning runs optimally for the given individual (Mareš, 2004).

Nowadays, we cannot think only about the given mutual bipolarity but also about other factors (the possibility of using academic materials in LMS and LCMS as a straight support of classical way of education) which influences the quality of educational process while these factors have crucial effect on the development of intellectual and cognitive skills of students. To correctly understand the all processes in the educational system it is possible to use various methods of modelling. By modelling the educational process we understand an activity which allows us to think about its use in the real world on the bases of acquired knowledge; and equally, consciously by fulfilling pedagogical and psychological principles affect it in a way to reach its effectiveness and optimization.

By Mcllrath and Huitt (2005) most current models that categorize the variables or explanations of the many influences on educational processes today stem from Carroll's (1963) seminal article defining the major variables related to school learning. Carroll specialized 
PROBLEMS

OF EDUCATION

IN THE $21^{\text {st }}$ CENTURY

Volume 50, 2012

in language and learning, relating words and their meanings to the cognitive concepts and constructs which they create (Klausmeier \& Goodwin, 1971). In his model, Carroll states that time are the most important variable to school learning. A simple equation for Carroll's model is: School Learning $=f$ (time spent/time needed).

When modelling the educational process it is necessary to draw from interaction understanding, from mutual social interactions of participants of the educational process. A „general model of educational process“, was thus created, which includes wider environs, input factors, the process itself and its products (immediate results and long-term effects). (Balogh and Turčáni, 2011)

The aim is to create a functional communication control model in LMS system by means of the created model in Petri nets. It is necessary to create a universal e-course model in LMS by which the pedagogue's and student's activity would be represented in the course and in arbitrary subjects e-courses would be created according to similar models. The model has been created so that it would reflect the pedagogue's and the student's requirements. It would be enough modular, intelligible and clear and would not be too complicated. (Balogh and Koprda, 2012)

The benefit of educational process modelling using Petri nets is their formal description, which is complemented by a visual graphic depiction. This allows a precise and exact specification of the process, which facilitates elimination of ambiguity, vagueness and contradictions. Petri nets, besides the visual graphic expression, have also square defined mathematical fundaments, which can suitably be used in various software tools for the specification and analysis of computer-solved company processes. For the description of educational processes, such as passing through the study material in e-learning education, it is appropriate to use mathematic and graphic methods, where mostly serial machines are profitably used. However, they have certain limitations. The issue can be solved by means of Petri nets thanks to their precise and exact specification. (Balogh, Turčáni, and Burianová, 2010), (Magdin, Cápay and Mesarošová, 2011)

For the description of the communication between a man and a computer it is suitable to use graphic tools (Markl, 2003), allowing for suitably describing and expressing the interaction. The teaching interaction between a student and an information system managing the instruction is a complex process for which Petri nets should be applied.

Edge superimposition is one of the problems with interpretation of the model in Petri nets but in many cases it is necessary. This problem can be solved by marking each of the edges by means of various colours. This colour dissimilarity helps the identification of various process flows and also to understand the functionality of the model. Then it is possible to divide the model into each sector and thus name their components what helps identify each component's function, i.e. place appellation and transitions. (Balogh and Koprda, 2012)

\section{Methodology of Universal Model}

\section{E-course Model Production with Exam}

There are markings (tokens) in two places in the initial model state: Pedagogue (P800) and Student $(\mathrm{P} 0)$. Tokens symbolises the pedagogue's and the student's process while using LMS.

The place and transition numeration is specified. Places, where are the pedagogue's positions, begin with the number 8 what is the pedagogue's identification number. The second number identifies the sector (part of the model) where is a place. And there is the last number what is the pedagogue's place type:

- 0 entrance place - conditions to open a new lesson 
- 1 entrance place - conditions for lesson accessibility

- 2 entrance place - conditions to peruse the task

- 3 entrance place - conditions for lesson accessibility

Student gets into the first sector (introductory part) by registration into the course. This sector contains various information about the course e.g. subject information sheet, recommended literature, course requirement to successfully pass the course, links of web pages referring to the themes, etc. These choices are represented by places P101 to P106. After the token (student) perused the selected information, he gets to the place P109 (Figure 1) from where he will be able to advance to the first lesson, if the pedagogue allows it.

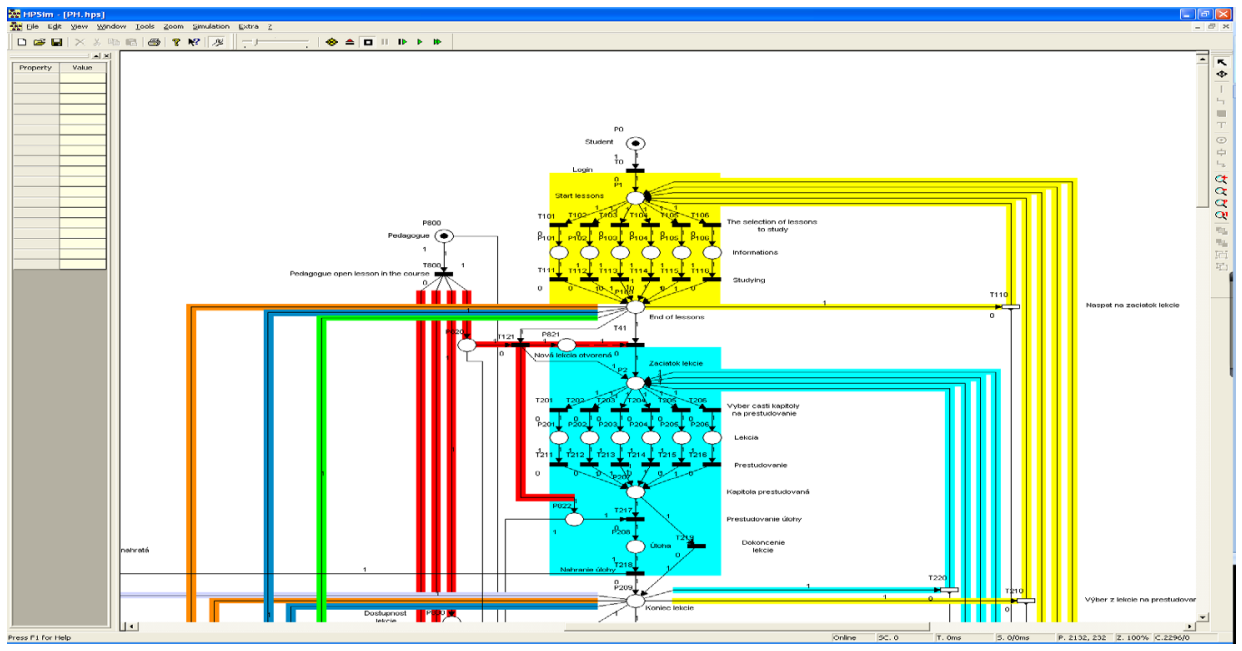

Figure 1: The incipient state of the model.

The Pedagogue's Task

On the created process model we can see that the information (articles, themes, textbook, and publications) is available for the student only if the pedagogue allows it. In this case, the pedagogue is the administrator of the course; he creates and modifies the course, uploads, adds or removes links and materials for study, checks students' activities, prepares, corrects, replies to tasks and many other functions that the system allows. The created model represents the student's perspective; therefore, the model does not contain the pedagogue's activity options and the important elements concerned about the student have been left. The pedagogue's task has thus simplified. He opens new lessons in the course, then assigns some tasks to it and finally, declassifies the exam so that the student would fulfil the requirements.

The transition realization is monitored in Figure 2 where the first numbers interpret the previous sector on the transitions T121 and T122. The second number interprets the next sector and the third is a type of transition where 1 is the transition for opening a new lesson and 2 is a transition from the previous lesson to the next. 
PROBLEMS

OF EDUCATION

IN THE $21^{\text {st }}$ CENTURY

Volume 50, 2012

50, 2012

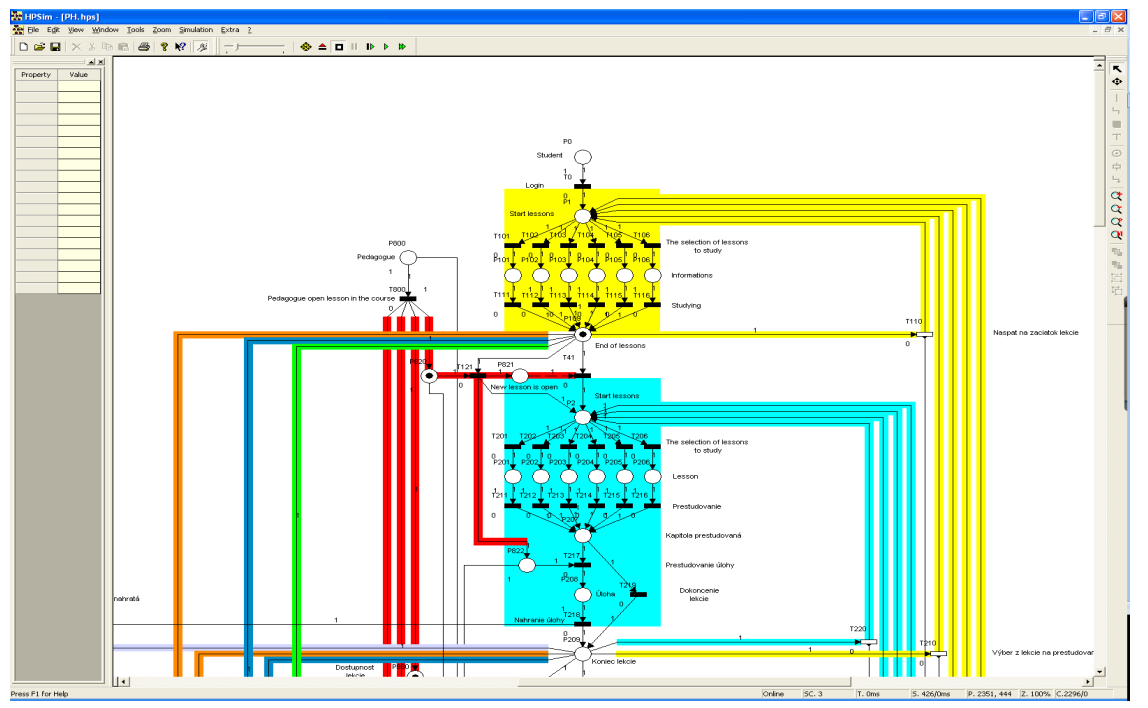

Figure 2: Before transition realization.

\section{E-course Lessons}

Courses in LMS are divided into individual lessons according to the course of study of a particular subject. It contains study materials, interactive animation, pictures, tasks, autotests, tests, exercises, etc. Lessons can be divided according to various criterions e.g. theme, content, time, etc. And according to settings, students can set linear or ramified education. It is always the pedagogue who sets these parameters and who determines the style and the rate of the educational process. The number and the content of the lessons are not limited, i.e. PX01 PX06, where $\mathrm{X} \nabla \mathrm{N} \mathrm{N}=\{1,2,3 \ldots\}$. The number of lessons does not affect the function of the model.

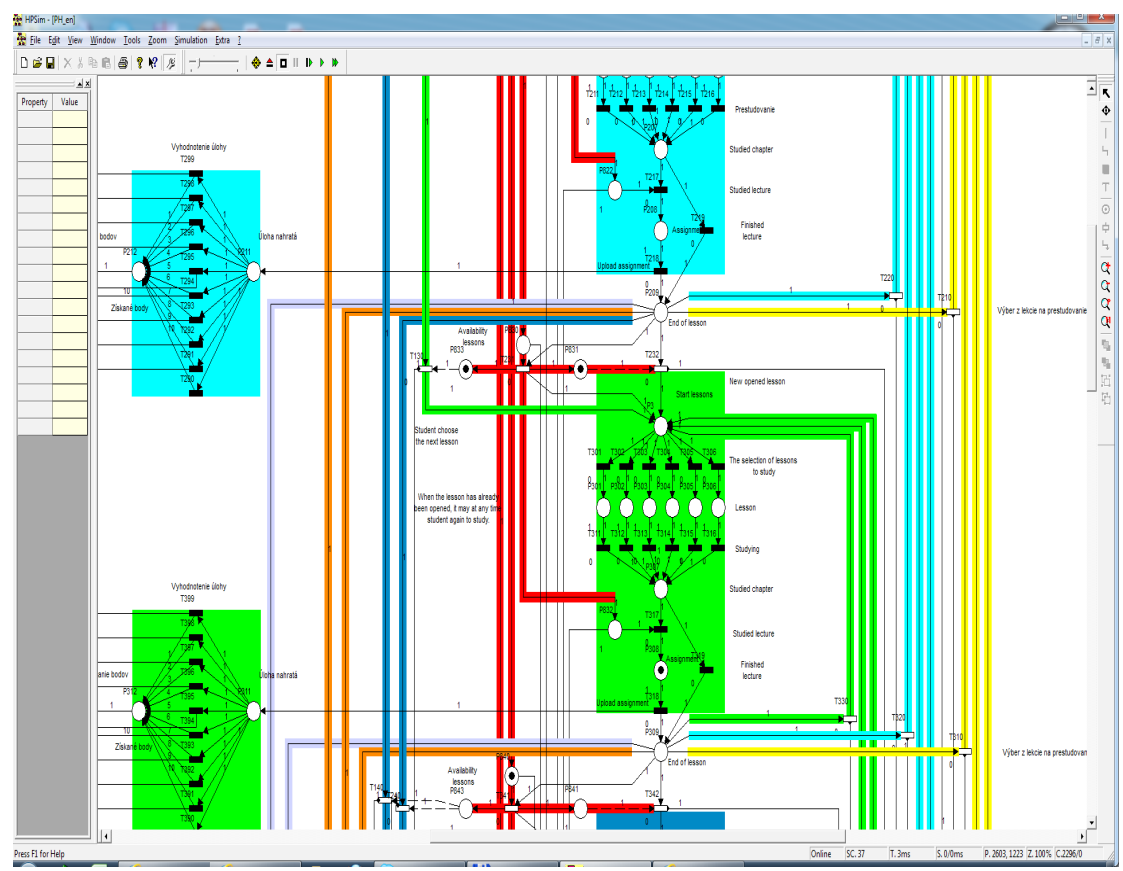

Figure 3: Student's transition through the lesson. 
After the student passed the task or perused the lesson, he is able to return to the previous lessons which he had already passed successfully (Figure 4) or is able to shift to another new lesson. Student can choose from the previous lessons to which he wants to return and chooses from the transitions T440, T430, T410, (TXX0). The marking logic of these transitions is:

- 1. number identifies the current sector (in this case 4)

- 2. number is the number of sector (lesson) where the student wants to get $(3,2,1)$

- 3. number (0), is a intersectional transition

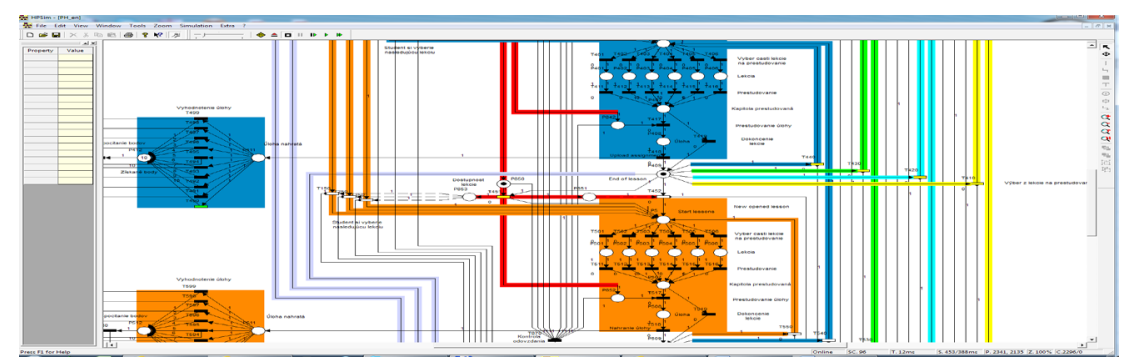

Figure 4: The choice of previous lessons.

Inhibitive and test edges were used in the model, then also deterministically types of transitions, places with a given capacity and various IF-THEN rules. Procedural e-course model designed in LMS contains other important parts e.g. scoring, the student's continuous assessment and the student's exam results.

The sequence shortening and imagery enlarging of educational processes in certain subjects were the consequence, purpose and prospective asset of the modelling.

\section{Discussion}

As Internet use has proliferated, e-learning systems have become increasingly popular. Many researchers have taken a great deal of effort to promote high quality e-learning environments, such as adaptive learning environments, personalized/adaptive guidance mechanisms, and so on. These researches need to collect large amounts of behavioural patterns for the verification and/or experimentation. However, collecting sufficient behavioural patterns usually takes a great deal of time and effort. When we solve to this problem, we can use browsing behaviour model based on High-Level Petri Nets (HLPNs) to model and generate students' behavioural patterns (Chang, Huang and Chu, 2009).

The idea of Chang et al. (2009) confirmed by other authors of professional publications, who point out that the importance of advanced information and communication technologies, such as education has increased significantly during the past few years. In order for electronic learning systems making use of these technologies to be successful, effective and of a quality comparable to some of the traditional educational learning systems, the electronic learning systems must be designed and constructed with care, using a scientific approach embracing well designed procedures and techniques (Drlík and Skalka, 2011).

E-learning has become an increasingly popular learning approach in universities due to the rapid growth of web based technologies. E-learning implementation at traditional universities as well as creating of any kind of virtual universities is a long-lasting and complicated process. It is necessary to see the e-learning implementation as a continuous and iterative process. The points of the entry into this process will vary depending on the institutional context and personal 
PROBLEMS

OF EDUCATION

IN THE $21^{\text {st }}$ CENTURY

Volume 50, 2012

skills of the teacher. It is becoming increasingly clear that there are many reservations, worries, objections and questions about e-learning from the pedagogical, professional, and sociological point of view that must be taken seriously (Barajas and Gannaway, 2000).

\section{Conclusions}

This study demonstrates the use of Petri Nets as applied to the interaction in a Collaborative Environment in the educational context, particularly E-learning. The target function of LMS is the direction of communication as to the student's knowledge and abilities, thus changing the amount and demandingness of the materials submitted to the student. In the theory of management there is an obvious transition from combination procedures to sequence chains and optimized processes (the strategy of continuous assessment of the student instruction reflection, and based on that, adaptation of the following instruction, is comparable with the dual principle of identification and adaptive management). Most frequently, the personalization of e-learning courses is realized on the bases of extracted knowledge of usage data by means of the web log mining techniques, however, we focus on the personalization using Petri nets. Teachers from the academic year 2009/2010 have actively used this designed model in educational process. The example of use e-learning course is Computer architecture subject, the results of use this model has been published in various scientific educational conferences and journals.

The article deals with the teaching process modelling in the environment of the LMS. For creation of further electronic courses in the virtual learning environment the constituted model serves as a prototype. As far as the effectiveness of the created model is concerned, we can make ourselves certain when obtaining the relevant data from the feedback, i.e. questionnaire, but mostly from the adjusted log files of e-courses. Thus in a course we can find out for example usage analysis and certain rules of applicant behaviour. The found rules can then be visualized in a web graph.

By means of similar analyses we shall be able to gradually eliminate all the disturbing elements from the process models of e-courses created by Petri nets and also make other courses more effective and attractive to reach the highest possible effectiveness upon e-learning study of applicants.

\section{Acknowledgements}

This research is supported thanks to the Fund for supporting the Centres of Research and Development with internationally comparable quality of operations, Faculty of Natural Sciences, CPU Nitra, Slovakia.

\section{References}

Balogh, Z., \& Koprda, Š. (2012). Modeling of Control in Educational Process by LMS. DIVAI 2012. 9th International Scientific Conference on Distance Learning in Applied Informatics: Conference Proceedings. Štúrovo, Hotel Thermal, May 2-4, 2012. Nitra: UKF, 43-51.

Balogh, Z., Turčáni, M. (2011). Possibilities of modelling web-based education using IF-THEN rules and fuzzy petri nets in LMS. Communications in Computer and Information Science, 251 (1), 93-106.

Balogh, Z., Magdin, M., Turčáni, M., \& Burianová, M. (2011). Interactivity elements implementation analysis in e-courses of professional informatics subjects. Efficiency and Responsibility in Education 2011, 5-14.

Balogh, Z., Turčáni, M., Burianová, M., (2010). Modelling web-based educational activities within the combined forms of education with the support of applied informatics with an e-learning support. Proceeding of the 7th International Conference Efficiency and Responsibility in Education ERIE 2010, 14-23. 
Balogh, Z., Turčáni, M., Magdin, M., Burianová, M. (2012). Creating model educational processes using Petri nets implemented in the LMS. Efficiency and Responsibility in Education 2012: 9th

PROBLEMS OF EDUCATION IN THE $21^{\text {st }}$ CENTURY Volume 50, 2012 International Conference, FEM CULS Prague 7th - 8th June 2012. Prague: Czech University of Life Sciences, 2012, 7-16.

Barajas, M., Gannaway, G., (2000). Implementing E-learning in the Traditional Higher Education Institutions. Higher Education in Europe, 32-39.

Carroll, J. (1963). A model for school learning. Teacher College Record, 64, 723-733.

Chang, Y, C., Huang, Y, C., Chu, C, P. (2009). B2 Model: A Browsing Behavior Model based on HighLevel Petri Nets to Generate Behavioral Patterns for e-learning. Expert Systems with Applications, $36,12423-12440$.

Drlik, M., Skalka, J., (2011). Virtual faculty development using top-down implementation strategy and adapted ees model. Procedia - Social and Behavioral Sciences, 28, 616-621.

Klausmeier, H., \& Goodwin, W. (1971). Learning and human abilities. New York: Harper \& Row Publishers.

Magdin, M., Cápay, M., Mesárošová, M., (2011). Usage of interactive video in educational process to determine mental level and literacy of a learner, 14th International Conference on Interactive Collaborative Learning, ICL 2011 - 11th International Conference Virtual University, VU'11, 510-516.

Magdin, M., Turčáni, M., Balogh, Z., (2012). Modelling the transition of a student through an e-learning course based on his previous activities. Efficiency and Responsibility in Education 2012: 9th International Conference, FEM CULS Prague 7th - 8th June 2012. Prague: Czech University of Life Sciences, 2012, 354-363.

Mareš, J., (2004). E-learning and individual learning styles. Československá Psychologie, 48 (3), $247-$ 262.

Markl, J., (2003). HPSim 1.1 - uživatelská př́ručka, [online] Available at $<$ http://www.cs.vsb.cz/markl/ $\mathrm{pn} / \mathrm{hpsim}>$ [Accessed 28 November 2011].

McIlrath, D., \& Huitt, W. (1995). The teaching/learning process: A discussion of models. Valdosta, GA: Valdosta State University. Retrieved December 1999, from http://www.edpsycinteractive.org/ papers/modeltch.html

\section{Advised by Laima Railiene, University of Siauliai, Lithuania}

Received: October 25, 2012

Accepted: December 18, 2012

\begin{tabular}{|ll|}
\hline Zoltán Balogh & $\begin{array}{l}\text { PhD., Associate Professor, Department of Informatics, Faculty of Natural } \\
\text { Sciences, Constantine the Philosopher University in Nitra, Tr. A. Hlinku 1, } 949 \\
74 \text { Nitra, Slovakia. } \\
\text { E-mail: zbalogh@ukf.sk }\end{array}$ \\
\hline Martin Magdin & $\begin{array}{l}\text { PhD., Researcher, Department of Informatics, Faculty of Natural Sciences, } \\
\text { Constantine the Philosopher University in Nitra, Tr. A. Hlinku 1, } 94974 \text { Nitra, } \\
\text { Slovakia. } \\
\text { E-mail: mmagdin@ukf.sk }\end{array}$ \\
\hline Milan Turčáni & $\begin{array}{l}\text { Professor, Department of Informatics, Faculty of Natural Sciences, Constantine } \\
\text { the Philosopher University in Nitra, Tr. A. Hlinku 1, } 94974 \text { Nitra, Slovakia. } \\
\text { E-mail: mturcani@ukf.sk }\end{array}$ \\
\end{tabular}

